\title{
Current Virulence of Pyrenophora teres on Barley in Western Australia
}

\author{
Sanjiv Gupta, State Agricultural Biotechnology Centre, Division of Science and Engineering, Murdoch University, \\ Murdoch, Western Australia 6150, Australia; and Robert Loughman, Plant Pathology, Agriculture Western Austra- \\ lia, Baron-Hay Court, South Perth, Western Australia 6151, Australia
}

\begin{abstract}
Gupta, S., and Loughman, R. 2001. Current virulence of Pyrenophora teres on barley in Western Australia. Plant Dis. 85:960-966.

Studies on variation, occurrence, and distribution of virulence in Pyrenophora teres are helpful to identify effective sources of resistance that can be used for barley breeding in Western Australia. Seventy-nine isolates of Pyrenophora teres were collected from different barley fields of Western Australia in 1995-96. Seventy-four induced net type symptoms (P. teres f. teres) and five induced spot type symptoms ( $P$. teres $\mathrm{f}$. maculata). Net type isolate responses on 47 barley lines were similar to the range of responses induced by nine historical isolates collected in the region between 1975 and 1985. These net type isolates were classified into two distinct groups based on virulence to the cultivar Beecher. Isolates were further classified into eight groups based on minor pathogenic variation among the population. The virulence phenotype present in an eastern Australian isolate was not observed in any isolates collected from Western Australia. An analysis of variance on a subset of 12 net type isolates indicated a significant line $\times$ isolate interaction $(P<0.001)$, with the interaction term variance component four times larger than the error variance. Based on these studies, the virulence among net type isolates has remained stable in Western Australia for the last 19 years. Spot type isolates were collected from a wider geographic area than previously reported and varied in virulence based on response to barley line Herta. Variation in spot-type isolates is reported for the first time from the region. The results from this study are being used in the development of resistant varieties.
\end{abstract}

Additional keywords: barley differential set, hierarchical classification

Net blotch, caused by Pyrenophora teres Drechs. (anamorph: Drechslera teres (Sacc.) Shoemaker), is a prominent foliar disease of barley (Hordeum vulgare L. emend. Bowden) in Western Australia $(19,46)$, as well as elsewhere in the world $(13,28,31,34,39,41)$. Two types of leaf symptoms are associated with the net blotch disease: the net type, caused by $P$. teres $\mathrm{f}$. teres, which causes horizontal and vertical crisscrossed dark brown venation that sometimes turns chlorotic; and the spot type, caused by P. teres f. maculata, which causes dark brown circular or elliptical spots accompanied by chlorosis of the surrounding leaf tissue $(20,32)$. Both pathogens reduce yield $(7,11,22,23,27,35,36)$, mainly through reduced grain size, which may impair the brewing quality of malting barley. Yield loss experiments conducted in Western Australia demonstrated a $17 \%$ yield decrease in barley cultivar Beecher due to net type net blotch (30). In a more detailed study, cultivar Dampier had a mean yield reduction of $21 \%$ with a maximum loss of $37 \%$ (16). For spot type, yield losses

Corresponding author: Sanjiv Gupta

E-mail: sanjiv@central.murdoch.edu.au

Accepted for publication 22 May 2001.

Publication no. D-2001-0702-01R

(C) 2001 The American Phytopathological Society varied from 3 to $22 \%$ in cultivars Beecher and O'Conner in Western Australia (17).

Studies on the occurrence and distribution of different virulence types of $P$. teres are essential to identify useful forms of resistance and assist in the development of future barley breeding strategies. Pon (26) first reported the variation in virulence in $P$. teres f. teres isolates in the United States. Since then, various studies have been conducted to understand the pathogenic variation and prevalence of pathotypes of $P$. teres around the globe using a range of differential barley lines (1$3,9,10,12-15,20,25,29,34,39,40)$ and also restriction fragment length polymorphism (RFLP) and random amplified polymorphic DNA (RAPD) markers $(21,24,45)$.

In Western Australia where net blotch is endemic, three pathotypes of $P$. teres $\mathrm{f}$. teres were reported by Khan and Boyd (18). The occurrence and virulence of $P$. teres f. maculata was reported by Khan and Tekauz (20). A change in virulence was observed with the introduction of new barley cultivars in Western Australia. The incidence of net type net blotch declined in the 1970 s, and by the early 1980 s, $73 \%$ of $P$. teres $\mathrm{f}$. teres isolates were avirulent on the previously susceptible cultivars Beecher and Atlas (15). The moderately resistant cultivars Stirling and O'Connor became susceptible a decade after their release in Western Australia, indicating the ability of the pathogen population to change with cultivars. The change in virulence, adoption of high-yield production methods, and wide use of conservation tillage practices have contributed to the reemergence of net blotch as a threat to barley production. The objective of this study was to determine the virulence spectrum of current populations and assess possible changes in $P$. teres over the 19 years since it was last assessed by Khan (15) in Western Australia.

\section{MATERIALS AND METHODS}

Collection of $P$. teres isolates. In spring of 1995 and 1996, 79 net blotch infected leaf samples were collected from barley fields distributed across all barley growing regions of Western Australia (Fig. 1). The infected leaves from each location were placed in paper envelopes, dried, and stored at room temperature $\left(20\right.$ to $\left.25^{\circ} \mathrm{C}\right)$. Nine historical isolates of $P$. teres f. teres collected and lyophilized between 1975 and 1985 were supplied by the Plant Pathology culture collection, Agriculture Western Australia, South Perth. These nine isolates of $P$. teres $\mathrm{f}$. teres were used to compare the variation in virulence with current isolates (Fig. 1). One P. teres f. teres isolate from eastern Australia was supplied by the Queensland Department of Primary Industries, Toowoomba, Queensland, Australia.

Single-spore isolation and inoculum production. Leaf tissue with net blotch lesions was cut into 5- to 10-mm-diameter fragments, surface-sterilized in $0.5 \%$ sodium hypochlorite solution for $2 \mathrm{~min}$, and then double rinsed in sterile deionized water for $1 \mathrm{~min}$. Fragments were blotted dry and aseptically transferred to $2 \%$ water agar plates. Isolation plates were incubated at 15 to $18^{\circ} \mathrm{C}$ with $12 \mathrm{~h}$ near-UV light $/ 12 \mathrm{~h}$ dark. For the historical reference isolates, lyophilized culture fragments were transferred to $2 \%$ water agar plates and incubated as above. After 3 to 5 days, a single conidium representing each collection was transferred, using the needle under the microscope, to peanut oatmeal agar (POA) medium plates (33) and incubated for 2 weeks to induce sporulation.

Differential barley set. A set of 47 barley lines was used. The set comprised 22 lines used by Steffenson and Webster (34) and eight by Tekauz (39); the remaining 17 were cultivars from different regions of Australia. Most lines were supplied by Queensland Department of Primary Industries, Toowoomba, Queensland, Australia. 
Lines were sown in 10 -cm-diameter plastic pots in clumps of 10 seeds per line and two lines per pot using a pasteurized soil mix ( 2 parts river sand and 1 part peat moss with nutrients and trace elements, $\mathrm{pH}$ 6.8 to 7). The plants were grown in the glasshouse at 18 to $22^{\circ} \mathrm{C}$ for 2 weeks with an average day length of $12 \mathrm{~h}$ or until the second leaf was fully opened.

Inoculum and inoculation of host plants. Conidia were harvested from POA plates by adding sterile distilled water and rubbing with a rubber spatula. The spore suspension was filtered through gauze and adjusted to $2 \times 10^{4}$ conidia per milliliter. Two milliliters of this suspension was applied per pot of 20 seedlings (approximately $2 \times 10^{3}$ conidia per plant) using an airbrush sprayer. The plants were placed in a mist chamber, and leaf wetness was maintained at 16 to $18^{\circ} \mathrm{C}$ for $24 \mathrm{~h}$. Then the plants were returned to the glasshouse for symptom development. Thirteen (12 P. teres $\mathrm{f}$. teres and one $P$. teres $\mathrm{f}$. maculata) out of 89 (79 current +9 historical +1 Queensland) isolates were repeated to determine reproducibility of the infection types.

Scoring infection types. Infection types on the second leaves were scored 9 days postinoculation for net type net blotch and 11 days postinoculation for spot type net blotch using the scales of Tekauz (37).

Assessment of differential lines for net blotch reaction at the adult plant stage. For net type net blotch, all lines were sown in a randomized block design with two replicates at South Perth. Each plot comprised 10 to 15 plants as single $1-\mathrm{m}$ rows. Barley straw infested with net type net blotch was applied at $50 \mathrm{~g} / \mathrm{m}^{2}$ at the seedling (four- to five-leaf) stage. Plants in each plot were assessed according to Tekauz (37) by assessing leaves on which infection had advanced by anthesis (flag-1 and flag-2 leaves).
Statistical analysis. In this study, seedling responses to $P$. teres isolates were classified using the package GEBEI (University of Queensland) by applying an agglomerative hierarchical classification procedure (43) with squared Euclidean distance as the measure of similarity among entries for the 47 barley lines and incremental sum of squares (ISS) as the grouping strategy $(4,5,42,44)$. To determine the optimal truncation points for use with the hierarchical classification method, we considered the effectiveness of the partition of sums of squares among groups and the magnitude of the variation within groups (8). These were determined using the appropriate partition of the sums of squares for a one-way classification of the data matrix (6). The barley differential lines also were classified in this way. Duplicate seedling infection responses were subject to analysis of variance using the package GENSTAT.

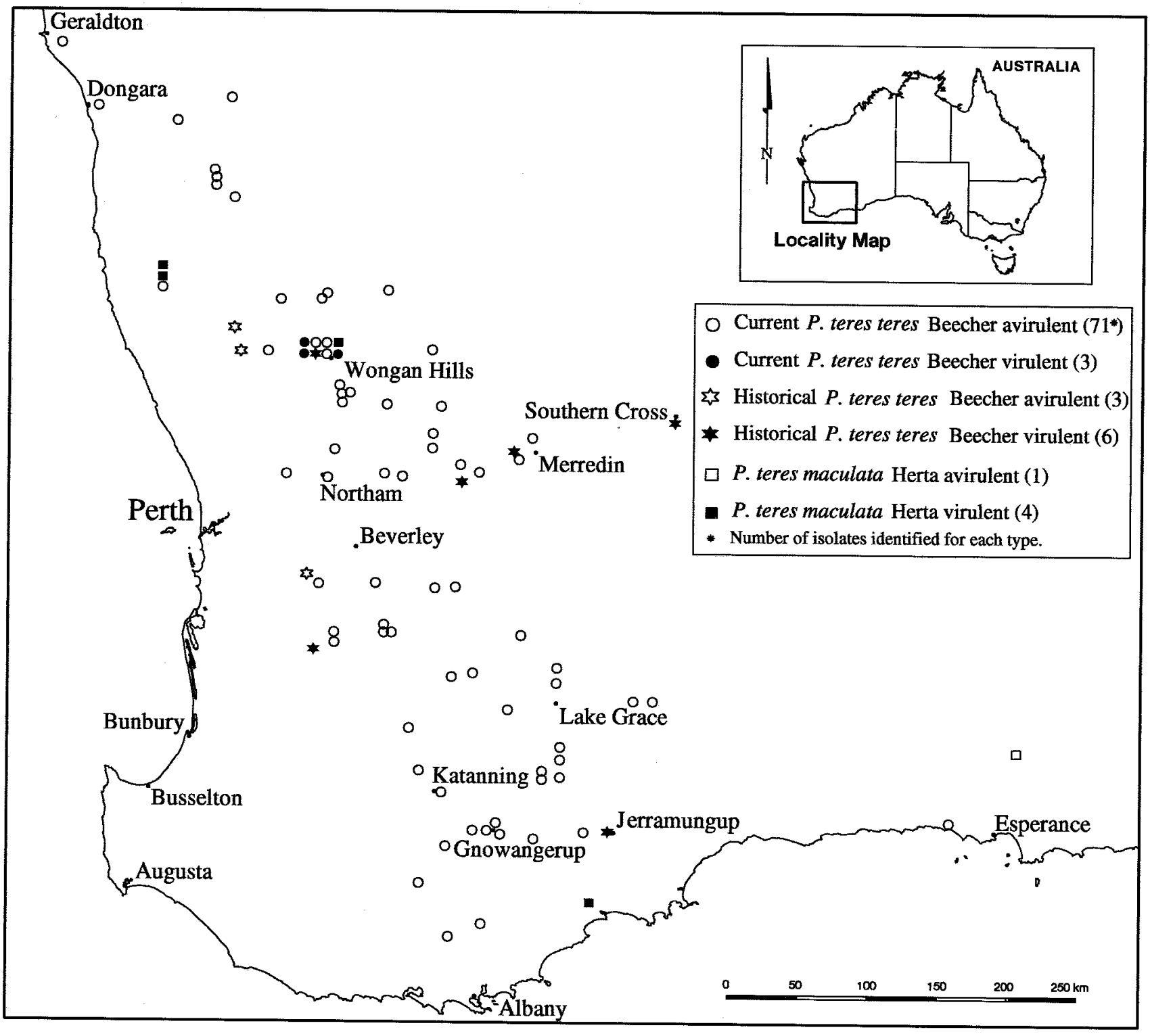

Fig. 1. Collection sites of Pyrenophora teres isolates and distribution of its pathotypes in Western Australia. 


\section{RESULTS}

Net type and spot type net blotch were widely distributed in the barley growing regions of Western Australia. The distribution of the obtained isolates according to their main distinguishing virulence characteristics (based on cv. Beecher for net type net blotch and cv. Herta for spot type net blotch) is shown in Figure 1.

$P$. teres f. teres isolate classification. The number of groups used for detailed examination was determined from the partitions of the sums of squares among the groups, the mean squares for the variation within groups, and the number of members within groups. The eight group level was chosen for further analysis. At this level of truncation, relatively high proportions of the variation due to differences in isolate means across barley lines (57\%) and differences in patterns across the barley lines (62\%) were partitioned among groups.

Isolate groups (IGs) had 2 to 45 isolates, which were relatively homogenous within each group (Fig. 2). The nodes of the dendrogram and the eight terminal groups were labeled using the fusion point that they represented in the sequence of classi- fication. In the dendrogram, groups that were more similar fused earlier.

Ninety-six $(84+12$ repeat) isolate responses were considered as two major isolate groups (IGs) that differed strongly for cluster at node 89 specifically in line groups LG8 and LG31 (Fig. 2) for infection types in lines Beecher, Hazera, Atlas, and Kombar (Fig. 3). Isolates comprising cluster 94 induced low infection types averaging from 2.0 to 3.6 on these line groups, while those comprising cluster 89 induced high infection types averaging 6.4 to 7.8 . Cluster 89 isolates also induced low average infection type on Clipper and more on members of LG10 (Prato and Steptoe, Fig. 3) compared to cluster 94 isolates.

The cluster at node 89 was comprised of two small IGs, 48 and 78. These two IGs were similar to each other except group 48 isolates induced 0.7 to 1.0 unit higher disease on barley line groups LG31, LG8, LG10, and LG30. IG48 isolates were all collected from Wongan Hills Research Station during the current survey and induced a high infection type $($ mean $=8)$ on line Dampier, a universal susceptible (raw

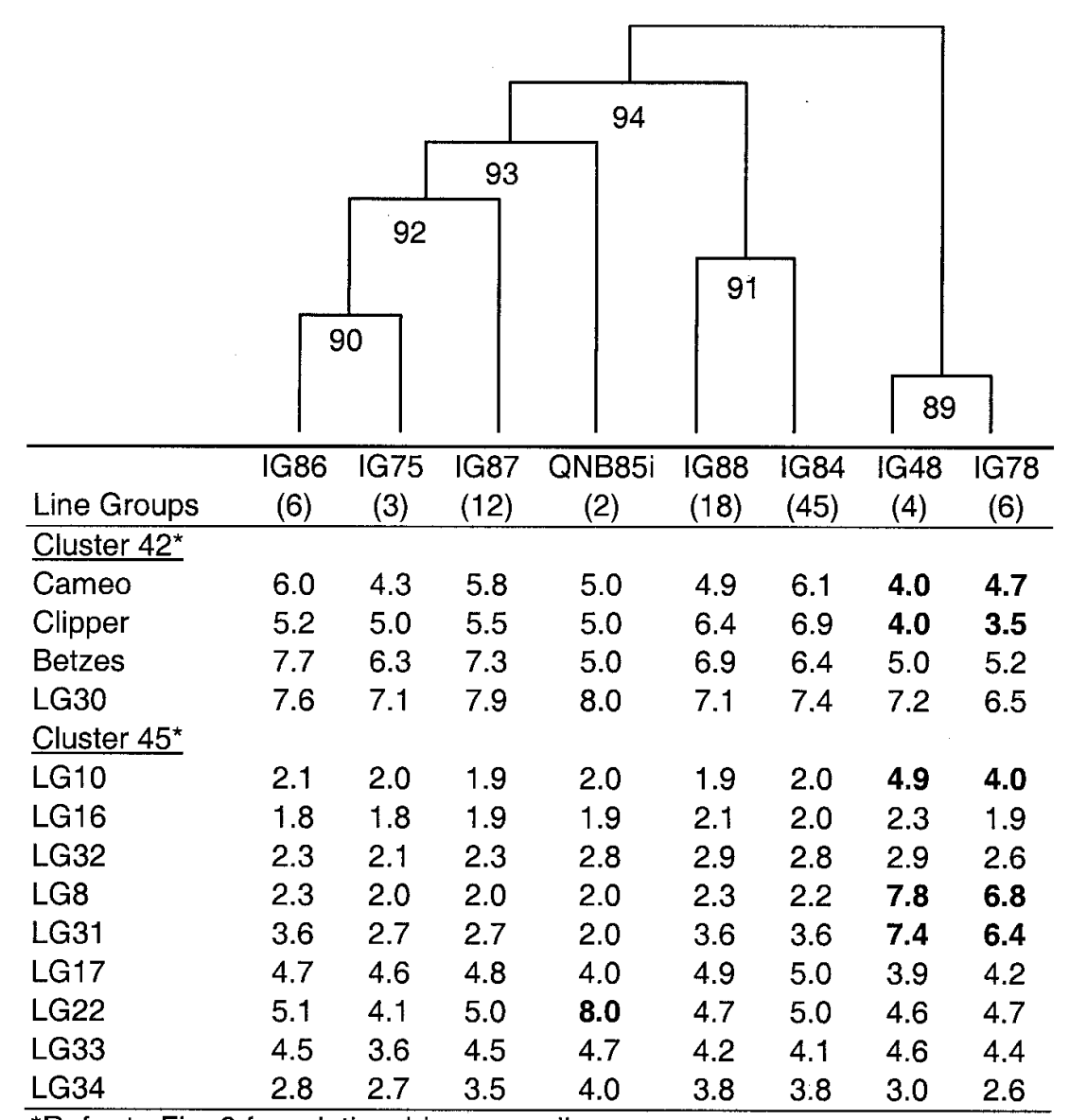

${ }^{\star}$ Refer to Fig. 3 for relationship among line groups

Fig. 2. The tabulated mean responses of 47 lines as 13 line groups (LG) on the basis of seedling net type Pyrenophora teres response from 96 tests using 84 isolates (including 12 repeats) clustered into eight isolate groups (IG). Numbers in bold indicate major contributions to the different groupings. The dendrogram depicts the relationship among groups of isolates. The number of isolates in each group is indicated in brackets. data not shown). IG78 isolates were all historic isolates collected from a range of environments and induced a moderately high $($ mean $=6)$ infection type on line Dampier (raw data not shown).

The second main cluster, fusing at node 94, contained members with low disease response on LGs 8 and 31 (Fig. 2). These six groups (including the eastern Australian isolate QNB85i) had patterns of response that differed in various degrees from each other. Cluster 91 comprised the majority of isolates (63, of which 8 were repeat tests), which fell into two similar groups, 88 and 84, differing mainly in their response on Cameo (a mean infection type difference of only 1.2, raw data not shown). The responses of other line groups to these two isolate groups were mostly similar.

Duplicate responses of QNB85i grouped together, and the relation of this small group to other groups can be seen in the dendrogram (Fig. 2). QNB85i was similar to other non-Beecher attacking isolates except that it produced high reaction scores in LG22 on lines Corvette (infection type 9), Gilbert (infection type 8), and Grimmett (infection type 7) (individual data not tabulated). QNB85i was less virulent on Betzes compared with other similar IGs, namely 86,75 , and 87 , which had 6,3 , and 12 isolates, respectively. These groups remained separate until fusion at the 4 group level (cluster 92). IG87, which included a duplicate isolate, induced slightly higher mean reactions on Tifang (3.4 versus 1.5), CI4922 (3.9 versus 2.5), and Ming (3.8 versus 2.6)-members of LG34 - than on IGs 75 and 86 (raw data not shown). Isolates in group 86 differed slightly from those in group 75, inducing intermediate reaction scores compared with more resistant scores in Cameo, Betzes, LG31, LG22, and LG33.

Twelve of the 84 isolates were screened in duplicate on separate dates to gauge the random variation in response of barley lines to isolates. For the purpose of classification, the duplicate responses were classified as individual responses. Ten of the duplicate isolates grouped with their corresponding replicate. One isolate had its replicates in the similar groups 88 and 84 , and the other had its replicates in groups 87 and 84.

Significant line $\times$ isolate effects $(P<$ 0.001 ) were observed among the 12 isolates tested in duplicate (Table 1). The variance component for line was large $\left(\sigma_{\mathrm{L}}{ }^{2}\right.$ $=2.369)$ compared with effects of isolate $\left(\sigma_{\mathrm{I}}^{2}=0.003\right)$ or interaction $\left(\sigma_{\mathrm{IL}}^{2}=0.493\right)$. Isolate $95 \mathrm{NB} 100$, which occurred in IG48, showed a significantly $(P<0.001)$ higher reaction score than other isolates on cvs. Atlas, Beecher, Hazera, Kombar, Prato, and Steptoe while it induced lower reactions than the majority of other isolates on cvs. Cameo and Clipper. Another isolate, QNB85i, induced significantly $(P<0.001)$ higher disease on lines Corvette, Gilbert, 
Golf, and Grimmett compared with other isolates.

Six IG84 isolates (95NB66, 95NB74, 95NB82, 95NB87, 95NB90, and 95NB119) induced little variation in response pattern among the barley lines, responses mostly being within 1 unit of score among each line for each isolate. These six isolates were generally similar to 95NB129 (IG88), except for a higher response on Cameo and Canadian Lake Shore $(P<0.001)$ (Table $1)$.

P. teres f. maculata isolate classification. Only five of 79 isolates induced spot type symptoms. These isolates originated from Badgingarra and Wongan Hills (central agricultural areas) and Mt. Ridley and Palinup River (southern agricultural areas) (Fig. 1). Seedling infection types for these isolates are shown in Table 2. Isolate 95NB117 showed higher (intermediate) reaction scores on barley lines Atlas, Clipper, Harbin, Moondyne, Rojo, and Steptoe compared with other isolates. This isolate also induced a resistant reaction on Betzes and Herta compared with intermediate or susceptible reaction scores for the other isolates.

Reaction to $P$. teres f. teres at adult plant stage. Net type expression in the field showed avirulence on line Beecher (Table 3). In field grown adult plants, net type net blotch reactions were similar to those in seedlings with Beecher avirulent isolates (adult plant responses shown in brackets in Figure 3). The reaction of Betzes was intermediate on adult plants compared with intermediate to susceptible reaction as seedlings.

Barley differential set classification. The grouping of barley lines was truncated at the 13 group level for further analysis. At this level of truncation, relatively high proportions of the variation due to differences in barley line means across isolates (99\%) and differences in patterns across the isolates $(61 \%)$ were partitioned among groups.

Line groups (LGs) had from 1 to 10 members and were relatively homogenous within each group. The responses of the 47 barley lines were considered as two major clusters in the dendrogram (Fig. 3). Moderate to high seedling reaction scores were common among lines that formed cluster 42 (Fig. 2). This cluster consisted of LG30, a group of universally susceptible lines, the single member group Betzes, which was similar to LG30 but had lower reaction scores to most isolates (particularly

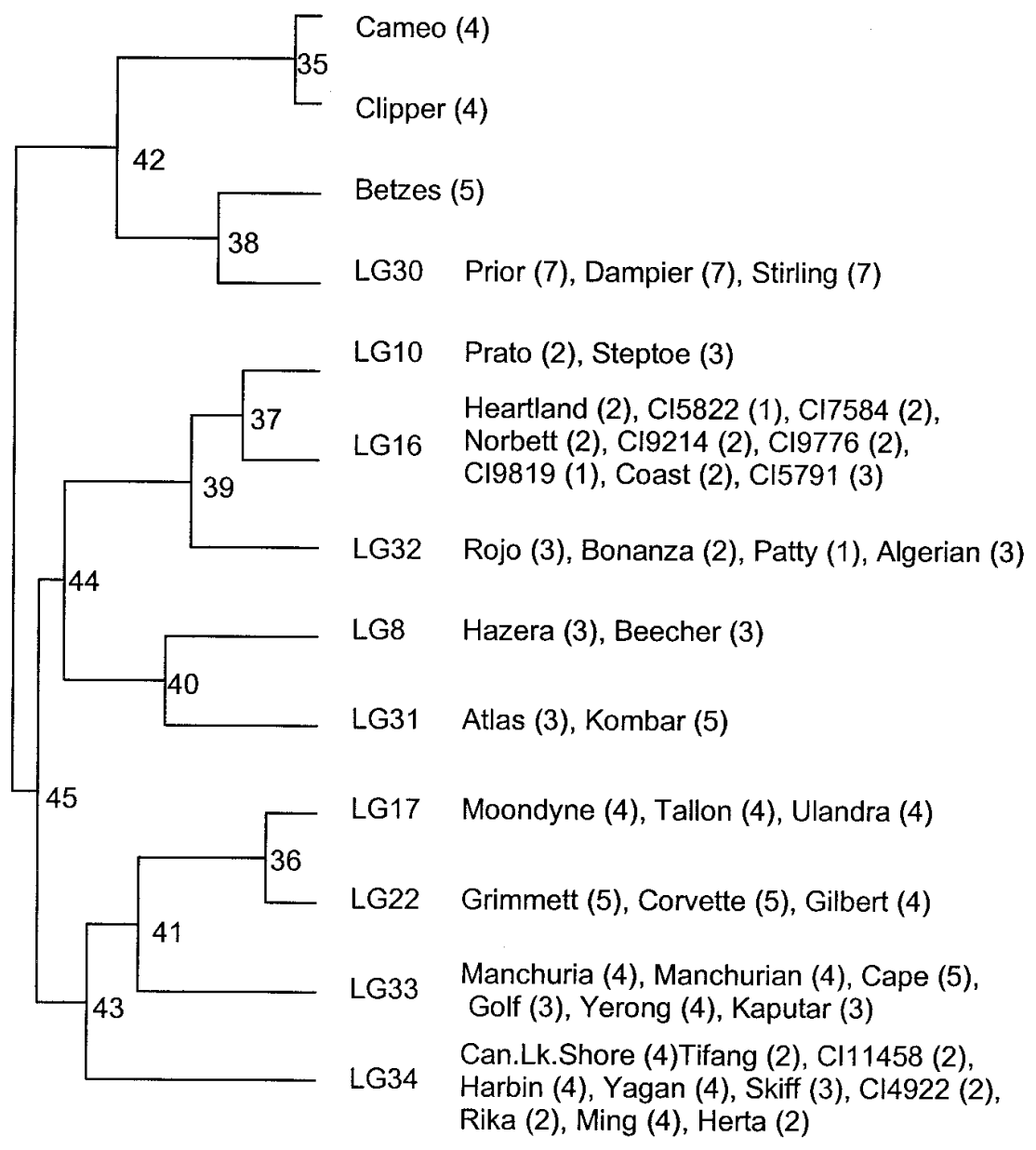

Fig. 3. The relationships and members of 13 groups of 47 lines classified from seedling net type net blotch response. The numbers in brackets are mean adult plant responses to a Beecher avirulent isolate.
QNB85i), and two single member groups, Clipper and Cameo. Clipper and Cameo were moderately susceptible to many isolates but were moderately resistant to the Beecher attacking isolates in IGs 48 and 78.

In cluster 45 , low to intermediate infection types were most common, but some high infection types occurred (Fig. 2). This cluster consisted of LGs 16 and 32, universally resistant lines; LG10, similar to LG16 but produced intermediate infection types with Beecher attacking isolates (IG48 and IG78); LGs 31 and 8, susceptible to Beecher virulent isolates but resistant to other isolates; LGs 17, 22, and 33, which generally had intermediate reaction scores (but Grimmett, Corvette, and Gilbert of LG22 were susceptible to the isolate QNB85i from Queensland); and LG34, resistant to intermediate to all isolates.

\section{DISCUSSION}

Both forms of $P$. teres were widely distributed across barley growing areas of Western Australia in 1995 and 1996, with $P$. teres f. teres isolates being more frequently recovered from surveyed crops.

Among P. teres f. teres isolates, two distinct virulence groups were detected. A small number of isolates was differentiated by their virulence on lines Atlas, Beecher, Hazera, and Kombar. The virulence represented by these isolates was reported in Western Australia by Khan and Boyd (18) as "Beecher virulent." Beecher previously occupied more than $75 \%$ of the state's barley producing area then declined rapidly in popularity in 1970s (15). It is now rarely grown (less than 0.3\%) in Western Australia, and the present distribution of isolates virulent on this cultivar is limited to Wongan Hills (Fig. 1). Wongan Hills isolates were collected at the Agriculture Western Australia Research Station, where a mix of Atlas and Dampier barley has been cultivated annually since 1980 to maintain a supply of net blotch infested residues for disease screening inoculum. Thus, the Atlas/Beecher virulence has been maintained in the P. teres f. teres population. Throughout other areas, this virulence was undetectable and isolates with greater virulence on cultivar Clipper occurred in association with the commercial cultivation of Clipper in the 1980s.

The majority of contemporary $P$. teres f. teres isolates were Beecher avirulent, and comparatively little variation existed among these. Further virulence previously identified in Western Australia by Khan and Boyd (18) on cultivar Algerian (CI1179) was not detected among the contemporary population of the pathogen.

The variation in reaction of the barley lines to infection with the range of isolates arose from both genetic and random effects. When the size of these components was estimated from a subset of isolates, the component of variance for the isolate $x$ 
line interaction was four times larger than the error variance component. While some barley lines gave very distinctive responses to different $P$. teres f. teres isolates, the degree of variation of other isolates was small and similar to the variation induced by random effects.

Among the 12 isolates tested as duplicates, 10 had responses grouped together following classification. The analysis of variance for these isolates confirms the major differences observed among the groups of Beecher virulent, Beecher avirulent, and Queensland types. The two remaining duplicated isolates, 95NB69 and $95 \mathrm{NB} 70$, had replicate responses allocated to different groups upon classification. For 95NB70, the duplicate responses were allocated to the very similar IGs 88 and 84 , while the 95NB69 duplicate responses were allocated to the generally less similar IG87 and IG84. However, the response data for these isolates indicated that the duplicates differed by not more than a reaction score of 1.0 for 16 to 18 of the 47 lines. It is possible that by chance, this was sufficient to give these a pattern of response more like that of other isolates than like their own. While small repeatable differences were observed between isolates in groups 88 and 84 of cluster 94 (Table 1), it appears that some of the variation observed within this cluster has little biological significance except for QNB85i, which however is not relevant to Western Australia. This analysis on isolates in duplicate suggested that the reaction scores of differ- ent $P$. teres $\mathrm{f}$. teres isolates are repeatable with great reliability.

Pathotypes of P. teres $\mathrm{f}$. teres prevalent in Western Australia can be differentiated using cvs. Beecher, CI 9214, and Dampier or Stirling or Prior (Table 3). On this basis, two pathotypes of $P$. teres $\mathrm{f}$. teres are differentiated. Beecher avirulence (depicted by the clusters of isolates at node 94, Fig. 2) is common in the population. Minor biological variation in varietal response observed among Beecher avirulent groups of Western Australian isolates is of limited immediate application for resistance breeding.

Western Australian pathotypes are different from those found in Queensland $(\mathrm{G}$. Platz, personal communication) and other parts of the world. Preliminary virulence studies on a limited set of 18 isolates indicated that there is a wide range of pathotypes of $P$. teres $\mathrm{f}$. teres in Queensland (25). The reference isolate from Queen- sland (QNB85i) was virulent on Grimmett, Corvette, Golf, and Gilbert, which clearly differentiated this isolate from Western Australian isolates. It appears this is a biological response on Grimmett likely to have arisen in Queensland in response to the commercial cultivation of this cultivar. In the absence of commercial plantings of this and the other three cultivars in Western Australia, there appears to have been no opportunity for virulence to have increased in the Western Australia P. teres f. teres population. Twenty-two barley lines in this study were the same as those used by Steffenson and Webster (34). Seven of the 22 lines were found to be resistant to all Western Australian isolates compared with 10 out of 22 in the studies of Steffenson and Webster (34) with California P. teres $\mathrm{f}$. teres isolates. None of these 22 lines was susceptible to all Western Australian isolates, although this was the case for three other lines (Dampier, Stirling, and Prior)

Table 2. Reaction scores (1 to 9 scale) of a Herta avirulent isolate (95NB117) and four Herta virulent isolates of Pyrenophora teres f. maculata on barley differential lines ${ }^{\mathrm{a}}$

\begin{tabular}{lccccc}
\hline & \multicolumn{5}{c}{ Isolate } \\
\cline { 2 - 6 } Barley line & 95NB117 $^{\mathbf{b}}$ & $\mathbf{9 5 N B 9 7}$ & $\mathbf{9 5 N B 1 0 4}$ & $\mathbf{9 5 N B 1 0 6}$ & $\mathbf{9 5 N B 1 5 5}$ \\
\hline Atlas & $\mathbf{5}$ & 3 & 3 & 3 & 2 \\
Betzes & $\mathbf{2}$ & 5 & 5 & 5 & 5 \\
Harbin & $\mathbf{5}$ & 3 & 2 & 3 & 3 \\
Herta & $\mathbf{3}$ & 7 & 5 & 7 & 7 \\
Steptoe & $\mathbf{5}$ & 2 & 2 & 3 & 3 \\
\hline
\end{tabular}

a Only lines contributing to a significant interaction of line $\times$ isolate effects are shown (main contributing scores in bold).

${ }^{b}$ Isolate $95 \mathrm{NB} 117$ mean of 2 replicates, other isolates unreplicated.

Table 1. Reaction scores (1 to 10 scale) of a Beecher virulent isolate (95NB100), 10 Beecher avirulent isolates, and one Queensland isolate (QNB85i) of Pyrenophora teres $\mathrm{f}$. teres tested in duplicate on barley differential lines ${ }^{\mathrm{a}}$

\begin{tabular}{|c|c|c|c|c|c|c|c|c|c|c|c|c|}
\hline \multirow[b]{3}{*}{ Barley line } & \multicolumn{12}{|c|}{ Isolate } \\
\hline & \multirow{2}{*}{$\frac{\text { IG48 }}{95 N B 100}$} & \multicolumn{6}{|c|}{ IG84 } & \multirow{2}{*}{$\begin{array}{c}\text { IG88/ } \\
\text { IG84 }^{\text {b }} \\
\text { 95NB 70 }\end{array}$} & \multirow{2}{*}{$\frac{\text { IG88 }}{95 N B 129}$} & \multirow{2}{*}{$\begin{array}{c}\text { IG87/ } \\
\text { IG84 }^{\text {b }} \\
\text { 95NB 69 }\end{array}$} & \multirow{2}{*}{$\frac{\text { IG87 }}{95 \mathrm{NB} 95}$} & \multirow[b]{2}{*}{ QNB 85i } \\
\hline & & 95NB 119 & 95NB 66 & 95NB 74 & 95NB 82 & 95NB 87 & 95NB 90 & & & & & \\
\hline Algerian & 4 & 3 & 3 & 3 & 2.5 & 3 & 2.5 & 3.5 & 2.5 & 2 & 2.5 & 5 \\
\hline Atlas & 7.5 & 3 & 3.5 & 3 & 2.5 & 3 & 4 & 2.5 & 3.5 & 2.5 & 2 & 2 \\
\hline Beecher & 8 & 2 & 2 & 2.5 & 2 & 2 & 2 & 2 & 2 & 2 & 2 & 2 \\
\hline Betzes & 5 & 5.5 & 7 & 6 & 6.5 & 7 & 6.5 & 7 & 7 & 7.5 & 7.5 & 5 \\
\hline Cameo & 4 & 7 & 6 & 6 & 5.5 & 7 & 6 & 5.5 & 4.5 & 5.5 & 6 & 5 \\
\hline CI9214 & 2 & 2 & 2 & 2 & 2 & 2 & 2 & 2 & 2 & 2 & 2 & 4 \\
\hline Clipper & 4 & 7 & 6.5 & 7 & 6.5 & 7 & 6.5 & 6.5 & 6 & 6.5 & 6 & 5 \\
\hline Corvette & 4.5 & 5 & 6 & 5 & 4 & 5 & 5 & 4.5 & 4.5 & 6 & 5 & 9 \\
\hline Gilbert & 5 & 5.5 & 5 & 5 & 5 & 5 & 4.5 & 5 & 4.5 & 5 & 5 & 8 \\
\hline Golf & 5 & 4 & 4 & 4 & 4 & 4 & 4 & 3.5 & 3.5 & 4 & 4 & 8 \\
\hline Grimmett & 4 & 5.5 & 5.5 & 5 & 4 & 5 & 5 & 4.5 & 5 & 4.5 & 5 & 7 \\
\hline Hazera & 8 & 2 & 2 & 2 & 2 & 2.5 & 2 & 2.5 & 2 & 2.5 & 2 & 2 \\
\hline Herta & 2 & 3 & 4 & 3.5 & 3 & 4 & 3.5 & 3.5 & 4 & 3.5 & 3.5 & 4 \\
\hline Kombar & 7 & 4 & 3.5 & 4 & 4 & 4 & 4 & 4 & 4 & 3 & 3.5 & 2 \\
\hline Ming & 2.5 & 4 & 4 & 4 & 4 & 4 & 4 & 4 & 4 & 3.5 & 3.5 & 4 \\
\hline Moondyne & 5 & 5 & 5 & 5 & 5 & 5 & 5 & 6 & 5 & 5 & 5 & 3 \\
\hline Prato & 5.5 & 2.5 & 2 & 2 & 1.5 & 2.5 & 2 & 2 & 2 & 2.5 & 2 & 2 \\
\hline Rika & 2.5 & 4 & 4 & 3.5 & 3 & 3 & 4 & 3.5 & 4 & 3.5 & 4 & 4 \\
\hline Steptoe & 4 & 2 & 2 & 2 & 2 & 2 & 2 & 1 & 2 & 2 & 2 & 2 \\
\hline Tallon & 3 & 5 & 5 & 4.5 & 5 & 6 & 5 & 5 & 4.5 & 4 & 5 & 5 \\
\hline Yerong & 5.5 & 4 & 4 & 4 & 4 & 4 & 4 & 4 & 4 & 4 & 4 & 3 \\
\hline$P$ (line.isol) & & & & & & $<0.001$ & & & & & & \\
\hline LSD 5\% & & & & & & 0.7 & & & & & & \\
\hline CV\% & & & & & & 9 & & & & & & \\
\hline
\end{tabular}

a Only lines contributing to a significant interaction of line $\times$ isolate effects are shown (main contributing scores in bold).

${ }^{\mathrm{b}}$ One replicate occurred in both groups. 
from Australia. Steffenson and Webster (34) found Prato, Kombar, and Atlas to be susceptible to the majority of their isolates, whereas we found intermediate to susceptible reaction for these lines only to a minority of our isolates (those being Beecher virulent). The 13 pathotypes identified from California and elsewhere were different from Western Australian virulences.

Tekauz in 1990 (39) reported the occurrence of 65 pathotypes out of 219 P. teres isolates using 12 barley differential lines. Eight out of 12 lines were included in our study. The differential virulence in these eight lines in Canada provides sufficient evidence that the Canadian virulence spectrum of $P$. teres is different from Western Australia. Jonsson et al. (13) identified 14 pathotypes of $P$. teres $\mathrm{f}$. teres using 18 barley lines in Sweden. Nine of the 18 lines were the same as used in our study. Golf was susceptible to all the pathotypes in Sweden, whereas it was intermediate in our study, indicating virulence types in Sweden are different from Western Australia. Afanasenko and Levitin (2) reported as many as 80 pathotypes of $P$. teres $\mathrm{f}$. teres from Russia using seven differentials. More recently, Afanasenko et al. (1) reported a wide range of pathotype diversity for P. teres f. teres from Russia, Germany, Czech Republic, and Slovakia using 38 barley lines. P. teres f. teres virulence in Western Australia is unique and has been relatively stable in recent decades. This is likely due to a lack of selection pressure for pathogen virulence because highly resistant cultivars have not been grown in this region.

The barley lines used to differentiate isolate responses were identified from sets used previously $(15,25,34)$, but also included lines which are widely grown in Western Australia and elsewhere in Australia. The broad range of resistances was more than required to discriminate among the simple range of virulences present in Western Australia. Cultivar Beecher discriminated among the $P$. teres $\mathrm{f}$. teres iso-

Table 3. Lines that distinguish net type Pyrenophora teres isolates tested on seedlings or adult plants, and their reactions

\begin{tabular}{lccccc}
\hline Isolate & $\begin{array}{c}\text { Dampier or } \\
\text { Stirling or Prior }\end{array}$ & CI 9214 & Beecher & $\begin{array}{c}\text { Corvette or } \\
\text { Grimmett }\end{array}$ & Betzes \\
\hline Beecher avirulent & $\mathrm{S}^{\mathrm{a}}$ & $\mathrm{R}$ & $\mathrm{R}$ & $\mathrm{I}$ & MS-S \\
Beecher virulent & $\mathrm{S}$ & $\mathrm{R}$ & $\mathrm{S}$ & $\mathrm{I}$ & $\mathrm{I}$ \\
QNB85i & $\mathrm{S}$ & $\mathrm{R}$ & $\mathrm{R}$ & $\mathrm{S}$ & $\mathrm{I}$ \\
Beecher avirulent & $\mathrm{S}$ & $\mathrm{R}$ & $\mathrm{R}$ & $\mathrm{I}$ & $\mathrm{I}$
\end{tabular}

(adult)

a $\mathrm{S}=$ infection types $\geq 7, \mathrm{MS}=$ infection type $6, \mathrm{I}=$ infection types 4 to $5, \mathrm{R}=$ infection types 1 to 3 .

Table 4. Lines that distinguish spot type Pyrenophora teres isolates tested on seedlings, and their reactions

\begin{tabular}{lccc}
\hline Isolate & Coast or Cape & Skiff or Norbert & Herta \\
\hline Herta avirulent & $\mathrm{S}^{\mathrm{a}}$ & $\mathrm{R}$ & $\mathrm{R}$ \\
Herta virulent & $\mathrm{S}$ & $\mathrm{R}$ & $\mathrm{S}$ \\
\hline
\end{tabular}

${ }^{a} \mathrm{~S}=$ infection types $\geq 7, \mathrm{MS}=$ infection type $6, \mathrm{I}=$ infection types 4 to $5, \mathrm{R}=$ infection types 1 to 3 . delimit the extent of variation among the $P$. teres $\mathrm{f}$. maculata population would be an important prelude to breeding for resistance to this pathogen.

The differential responses of barley lines at the seedling and adult plant stage were studied by Tekauz (38) and Douiyssi et al. (9). Expression of low infection types on seedlings can appear as high infection types on adult plants, and vice versa, and is pathotype specific. Seedling glasshouse and adult field responses to $P$. teres observed in the current study were very similar, with only minor variation in disease reaction observed as lower adult infection types in Betzes and Clipper. The current situation suggests that selection for resistance to the common forms of P. teres f. teres using seedling tests will largely reflect adult plant responses when those resistances are deployed in the field.

In conclusion, the current virulence spectrum of $P$. teres has remained stable in Western Australia in the last two decades, except that $P$. teres $\mathrm{f}$. maculata has been found to be more widely distributed within the region than previously reported. Work is in progress to pyramid diverse resistances in breeding programs.

\section{ACKNOWLEDGMENTS}

We thank Ian Goss and Chris King for their technical support. We also thank Grains Research and Development Corporation, Grain Pool of Western Australia, Joe White, and Kirin Maltings for financial support.

\section{LITERATURE CITED}

1. Afanasenko, O. S., Hartleb, H., Guseva, N. N., Minarikova, V., and Janosheva, M. 1995. A set of differentials to characterize populations of Pyrenophora teres Drechs. for international use. J. Phytopathol. 143:501-507.

2. Afanasenko, O. S., and Levitin, M. M. 1979. The population structure of the pathogen of net blotch of barley as regards its virulence. I. Identification of races. Mikol. Fitopatol. 13:230-234.

3. Arabi, M. I., Barrault, G., Sarrafi, A., and Albertini, L. 1992. Variation in the resistance of barley cultivars and in the pathogenicity of Drechslera teres f. sp. maculata and D. teres f. sp. teres isolates from France. Plant Pathol. 41:180-186.

4. Burr, E. J. 1968. Cluster sorting with mixed character types. I. Standardization of character values. Aust. Comp. J. 1:97-99.

5. Burr, E. J. 1970. Cluster sorting with mixed character types. II. Fusion strategies. Aust. Comp. J. 2:98-103.

6. Byth, D. E., Eisemann, R. L., and DeLacy, I. H. 1976. Two-way pattern analysis of a large data set to evaluate genotypic adaptation. Heredity $37: 215-230$.

7. Deadman, M. L., and Cooke, B. M. 1987. Effects of net blotch on growth and yield of spring barley. Ann. Appl. Biol. 110:33-42.

8. DeLacy, I. H., and Cooper, M. 1990. Pattern analysis for the analysis of regional variety trials. Pages 301-334 in: Genotype by Environment Interaction and Plant Breeding. Louisiana State University, Baton Rouge.

9. Douiyssi, A., Rasmusson, D. C., and Roelfs, A. P. 1998. Responses of barley cultivars and lines to isolates of Pyrenophora teres. Plant Dis. 82:316-321.

10. Gacek, E. 1985. Variabilities of pathogenicity of the Pyrenophora teres (Died.) Drechsl. 
fungus. Hodowla Rosl. Aklim. Nasienn. 29:41-50.

11. Hampton, J. G., and Arnst, B. J. 1978. The relationship between net blotch and yield loss in spring barley. Pages $18-1$ to $18-4$ in: Epidemiology and Crop Loss Assessment. Proc. APPS Workshop, Lincoln College, New Zealand.

12. Harrabi, M., and Kamel, A. 1990. Virulence spectrum to barley in some isolates of Pyrenophora teres from the Mediterranean region. Plant Dis. 74:230-232.

13. Jonsson, R., Bryngelsson, T., and Gustafsson, M. 1997. Virulence studies of Swedish net blotch isolates (Drechslera teres) and identification of resistant barley lines. Euphytica 94:209-218.

14. Karki, C. B., and Sharp, E. L. 1986. Pathogenic variation in some isolates of Pyrenophora teres f. sp. maculata on barley. Plant Dis. 70:684-687.

15. Khan, T. N. 1982. Changes in pathogenicity of Drechslera teres relating to changes in barley cultivars grown in Western Australia. Plant Dis. 66:655-656.

16. Khan, T. N. 1987. Relationship between net blotch (Drechslera teres) and losses in grain yield of barley in Western Australia. Aust. J. Agric. Res. 38:671-679.

17. Khan, T. N. 1989. Effect of spot-type net blotch (Dreschslera teres (Sacc.) Shoem.) infection on barley yield in short season environment of Northern Cereal Belt of Western Australia. Aust. J. Agric. Res. 40:745-752.

18. Khan, T. N., and Boyd, W. J. R. 1969. Physiologic specialization in Drechslera teres. Aust. J. Biol. Sci. 22:1229-1235.

19. Khan, T. N., Boyd, W. J. R., and Shipton, W. A. 1968. Barley diseases in Western Australia: Their distribution and pathogenic characteristics. J. Royal Soc. West. Aust. 51:123-128.

20. Khan, T. N., and Tekauz, A. 1982. Occurrence and pathogenicity of Drechslera teres isolates causing spot-type symptoms on barley in Western Australia. Plant Dis. 66:423-425.

21. Louw, J. P. J., Victor, D., Crous, P. W., Holz, G., and Janse, B. J. H. 1995. Characterization of Pyrenophora isolates associated with spot and net type lesions on barley in South Africa.
J. Phytopathol. 143:129-134.

22. Martin, R. A. 1985. Disease progression and yield loss in barley associated with net blotch, as influenced by fungicide seed treatment. Can. J. Plant Pathol. 7:83-90.

23. Mathre, D. E. 1997. Compendium of barley diseases. American Phytopathological Society, St. Paul, MN.

24. Peever, T. L., and Milgroom, M. G. 1994. Genetic structure of Pyrenophora teres populations determined with random amplified polymorphic DNA markers. Can. J. Bot. 72:915923.

25. Platz, G. J., Rees, R. G., and Galea, V. J. 1996. Virulence of net blotch in Australia. Pages 761-763 in: Proc. VII Int. Barley Genet. Sympos. Canada.

26. Pon, D. S. 1949. Physiologic specialization and variation in Helminthosporium teres. (Abstr.) Phytopathology 39:18.

27. Rintelen, J. 1969. Studies on yield losses caused by net blotch of barley (causal agent: Pyrenophora teres Drechsl., stat. con.: Helminthosprorium teres Sacc.). Z. Pflanzenkrankh. Pflanzenpathol. Pflanzenschutz 76:147-152.

28. Robinson, J., and Jalli, M. 1996. Diversity among Finnish net blotch isolates and resistance in barley. Euphytica 92:81-87.

29. Sato, K. 1994. Studies on the breeding and evaluation of germplasm for the resistance to net blotch in barley. Special Report Barley Germplam Center, Res. Institute Bioresources, Okayama Univ., Japan.

30. Shipton, W. A. 1966. Effect of net blotch infection on grain yield and quality. Aust. J. Exp. Agric. Anim. Husb. 6:437-440.

31. Shipton, W. A., Khan, T. N., and Boyd, W. J. R. 1973. Net blotch of barley. Rev. Plant Pathol. 52:269-290.

32. Smedegard-Petersen, V. 1971. Pyrenophora teres f. maculata f. nov. and Pyrenophora teres $\mathrm{f}$. teres on barley in Denmark. Pages 124-144 in: Yearbk. Royal Vet. Agric. Univ., Copenhagen.

33. Speakman, J. B., and Pommer, E. H. 1986. A simple method for producing large volumes of Pyrenophora teres spore suspension. Bull. Br. Mycol. Soc. 20:129-130.
34. Steffenson, B. J., and Webster, R. K. 1992 Pathotype diversity of Pyrenophora teres $\mathrm{f}$ teres on barley. Phytopathology 82:170-177.

35. Steffenson, B. J., Webster, R. K., and Jackson, L. F. 1991. Reduction in yield loss using incomplete resistance to Pyrenophora teres $\mathrm{f}$. teres in barley. Plant Dis. 75:96-100.

36. Sutton, J. C., and Steele, P. 1983. Effects of seed and foliar fungicides on progress of net blotch and yield of barley. Can. J. Plant Sci. 63:631-639.

37. Tekauz, A. 1985. A numerical scale to classify reactions of barley to Pyrenophora teres. Can. J. Plant Pathol. 7:181-183.

38. Tekauz, A. 1986. Effect of plant age and leaf position on the reaction of barley to Pyrenophora teres. Can. J. Plant Pathol. 8:380-386.

39. Tekauz, A. 1990. Characterization and distribution of pathogenic variation in Pyrenophora teres $\mathrm{f}$. teres and $P$. teres f. maculat from western Canada. Can. J. Plant Pathol. 12:141-148.

40. Tekauz, A., and Mills, J. T. 1974. New types of virulence in Pyrenophora teres in Canada. Can. J. Plant Sci. 54:731-734

41. Wallwork, H., Loughman, R., and Khan, T. N 1995. Biology and control of Drechslera diseases of barley in Australia. Pages 139-160 in Helminthosporia Metabolites, Biology, Plant Diseases Bipolaris, Drechslera, Exserohilum. J. Chelkowski, ed. Institute of Plant Genetics, Polish Academy of Sciences, Poznan.

42. Ward, J. H. 1963. Hierarchical grouping to optimise an objective function. J. Am. Stat. Assoc. 58:236-244.

43. Williams, W. T. 1976. Pattern analysis in agricultural science. Elsevier Scientific Publishing Company, Amsterdam.

44. Wishart, D. 1969. An algorithm for hierarchical classification. Biometrics 22:165-170.

45. Wu, H., Steffenson, B. J., You, L., and Oleson, A. E. 1993. Restriction fragment length polymorphisms of Pyrenophora species pathogenic to barley. (Abstr.) Phytopathology 83:887.

46. Young, K., and Loughman, R. 1995. Leaf diseases of barley. Pages 71-78 in: The Barley Book. M. Howes, ed. Department of Agricul ture, Western Australia, Perth. 